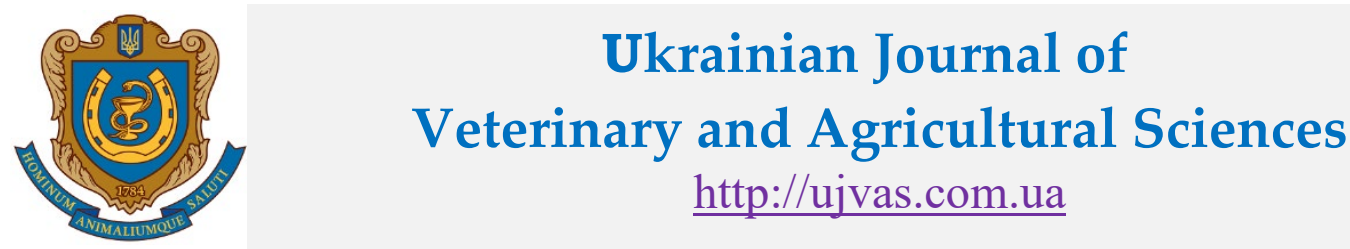

Stepan Gzhytskyi National University of Veterinary Medicine and Biotechnologies Lviv \begin{tabular}{l|l|l} 
original article & UDC 636.2 & doi: 10.32718/ujvas3-2.10
\end{tabular}

\title{
Histological study of eyelid in Algerian locale bovine
}

\author{
M. A. Fares ${ }^{1}$, D. E. Rahmoun ${ }^{1}$, M. A. Lieshchova ${ }^{2}$ \\ ${ }^{1}$ University of Mohamed Cherif Messaâdia, Souk Ahras, 41000, Algérie \\ ${ }^{2}$ Dnipro State Agrarian and Economic University, Sergii Efremov Str., 25, Dnipro, 49600, Ukraine
}

\begin{tabular}{l} 
Article info \\
Received 20.04.2020 \\
Received in revised form \\
25.05.2020 \\
Accepted 26.05.2020 \\
\hline Correspondence author \\
Mohamed Fares \\
Tel.: +213-549-542-606 \\
E-mail: faresamin1995i@gmail.com \\
\hline 2020 Fares M. A. et al. This is an \\
open-access article distributed under \\
the terms of the Creative Commons \\
Attribution License, which permits \\
unrestricted use, distribution, and \\
reproduction in any medium, \\
provided the original author and \\
source are credited.
\end{tabular}

Abstract

Ten pairs of eyelids of adult, healthy cattle of the local breed from the region of Guelma, Algeria, were collected at the slaughterhouse in order to carry out research to determine the structure, the components and to make a comparison with the results of this subject in other ruminants, classical staining techniques such as Hematoxylin \& eosin, Masson trichrome and silver nitrate were carried out in the histology laboratory on sections of these membranes, the studied parts were the upper eyelid and lower eyelid, medial and lateral canthus, the results observed were significant, there was a small increase in the thickness of the epidermis in the lower eyelid, and the small sebaceous glands which made the difference between the lower eyelid from local cattle, these glands originate near the basement membrane of the upper eyelids. Regarding the tarsal gland, empty its secretion onto the surface of the eyelid through a duct lined with typical stratified squamous epithelium.

Key words: bovine, eyelid, gland of Zeis, histology, tarsal gland.

\section{$(c)$ EY}

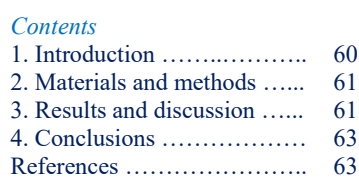

\section{Citation:}

Fares, M. A., Rahmoun, D. E., Lieshchova, M. A. (2020). Histological study of eyelid in Algerian locale bovine. Ukrainian Journal of Veterinary and Agricultural Sciences, 3(2), 60-63.

\section{Introduction}

The eyelids are mobile cutaneous-musculo-membranous blades covering part or all of the anterior part of the eyeball (Baker et al., 2019). The upper eyelid is much more mobile than the lower eyelid and completely covers the cornea when it is closed (Bharti et al., 2008; Watt et al., 2018). The eyelids have a double function in ruminant as in different animal spices: Globe protection; Lacrimal drainage (Gartner et al., 2007). They are limited to the orbital rim; beyond, the eyelids continue with the integuments of the face (Amakiri et al., 1979), in above the upper eyelid is limited by the lower edge of the eyebrow; whereas in below the lower eyelid is delimited by two skin furrows forming the palpébro-genien furrow of Charpy (Lang, 1997). This groove represents the adhesion of the underlying skin fascia to the periosteum and separates the lower eyelid from the cheek (Cvekl et al., 2009). From outside and inside there is no precise anatomical element separates the palpebral region from the temporal and nasal regions. And from the back the eyelid is separated from the orbit by the orbital septum, whereas by their free edge, each upper and lower eyelid delimits between them the palpebral slit. This is limited outside and inside by the canthi. Each eyelid is made up of particular integuments which are a very thin and conjunctive skin respectively covering the anterior and posterior surface of the eyelid (Bank, 1986), a fibro-elastic framework extending from the orbital rim to the free edge, composed of, of a peripheral part, the orbital septum, from a central part, the tarsus fixed to the orbital rim by the external canthus and internal canthus tendons. In conjunctival plan, the mucous lining the entire posterior surface of the eyelid, it gives way to the bulbar conjunctiva at the level of the upper fornix (Sakai, 1981; Cvekl et al., 2009). It is strongly adherent to tarsus. On the other hand, there is a cleavage plane between the conjunctiva and the Müller muscle in its upper half (Sajdak et al., 2019). It contains the accessory lacrimal glands. Other important components which are the special hairs (eyelashes) are in the upper eyelid of all species except in the cat (Zeiss et al., 2018), but in the lower eyelid the eyelashes are fewer in number in ruminant and horse absently in cat and dog, the tactile hairs may be present on or 
near the eyelids (Benoit et al., 2016), The most characteristic feature of eyelids is the tarsal glands, which were better developed in the upper eyelid .They are multilocular sebaceous glands with central ducts that are surrounded by a dense collagen plate, About the Innervation, the motor Müller's muscle is innervated by the sympathetic system. Whereas The lifting muscle of the upper eyelid is innervated by the upper branch of III (Bharti et al., 2008), and the superficial muscles are under the control of VII (facial). About the sensitive innervation (Bharti et al., 2008), the upper eyelid is innervated by the branches of Willis' ophthalmic nerve, and the lower eyelid is innervated by the suborbital nerve (terminal branch of the upper maxillary nerve) (Schwarz et al., 1999).

\section{Materials and methods}

Small parts from the eyelids skin were cut from carcass of healthy animals in Guelma slaughterhouse, in the east of Algeria, the collected parts of skin were put in a solution of formalin of concentration of $5.0 \%$ and $10.0 \%$, then been sectioned and placed in a coating cassette, and processed for paraffin sectioning. Thin sections of 5-7 microns were made with a CUT 4062 microtome with manual rotation. Some sections were stained by Hematoxylin \& eosin for the morphological study, some others were stained with silver nitrate, and the other parts were stained with Masson Trichrome stain for best observation and differentiation between collagen fibers and muscle fibers. The determination of the histological and cytological characteristics was carried out using an ocular microscope and a stereo MBS10 microscope. The quantitative study for the tissue compartments was carried out using the point S system; the data obtained were analyzed with $\mathrm{R}$ program.

\section{Results and discussion}

\section{Results}

The eyelids covered externally with Skin, and all studied areas covered internally by palpebral conjunctiva made with basal layer of cuboidal cells, one to three intermediate layers of polygonal cells, scattered among the epithelial cells goblet cells that are more numerous in the internal parts of the conjunctiva. there was no a significant increase in the thickness of corneal layer of all studied areas, while the thickness of epidermis was significantly increase of the lower eyelids (Table 1).

Table 1

Thickness of corneal layer and epidermis of eye lids of local Algerian bovine with Micrometer $(\mu \mathrm{m})$

\begin{tabular}{lcccc}
\hline \multicolumn{1}{c}{ Thickness } & Upper eyelid & Lower eyelid & Medial canthus & Lateral canthus \\
\hline Corneal layer & $19.17 \pm 1.11$ & $18.69 \pm 1.24$ & $21.71 \pm 1.09$ & $21.82 \pm 1.24$ \\
Epidermis & $105.77 \pm 5.71$ & $102.66 \pm 10.98$ & $94.05 \pm 6.69$ & $119.49 \pm 11.92$ \\
\hline
\end{tabular}

The epidermis became thin and thin in upper eyelids at area of prescience of tarsal glands, the melanin granules distributed between the cells of basal and spinosum stratum, and were organized within the hair follicles and dermal connective tissues. The basal membrane was less corrugated in the upper eyelids, lateral and medial canthus of the eye, while more corrugated in the lower eyelids. The dense irregular connective tissue of the dermis containing amounts of elastic fibers and large amount of collagen fibers in the tarsal plate with cross section of skeletal muscle of orbicularis muscle which penetrate the eyelids and scattered bundles of smooth muscle fibers. The eye lashes follicle located at marginal part of skin that are much numerous concentrated in the upper eyelid's areas (Fig. 1).

The eyelashes varying in extension and diameter. The eyelashes presence in double or triple rows in the upper and lower eyelids. Gland of Zeis smaller sebaceous gland that do empty their secretion into the follicle lashes there was a significant difference in the longitudinal section of the gland of Zeis of the lower eyelids compared with other studied areas (Fig. 2). These glands near the basement in lateral canthus, medial canthus, upper eyelids respectively while it becomes deeper in lower eyelid areas, About sweat gland of moll, ciliary gland, that consist of two portions secretary parts and duct system, the height of secretary parts lined with flattened cuboidal to tall columnar depending on the secretary status or activity of the cells. This secretary material appeared as irregular granular mass, which were most common, or spherical drops spread between the granular masses. Myoepthelial cells located basally to the secretary unit. These glands were smaller in lower eyelid and upper eyelid areas but became larger in medial canthus and lateral canthus areas progressively.

These glands began nearly the basement membrane in lateral eyelids, lateral canthus, medial canthus, upper eyelids areas respectively, while extended far distance in medial canthus, upper eyelids, lateral canthus then lower eyelids About Tarsal gland were multi lobular sebaceous gland embedded in the tarsal plate, about measurement there was no significant difference between lower and upper eyelids, neither between median and lateral canthus, whereas in the canthus was thicker than in the eyelids. They do not communicate with the hair follicle of the eyelashes (Fig. 3), the gland is very near the surface of the skin specially in the upper and lower eye lid (Fig. 4).

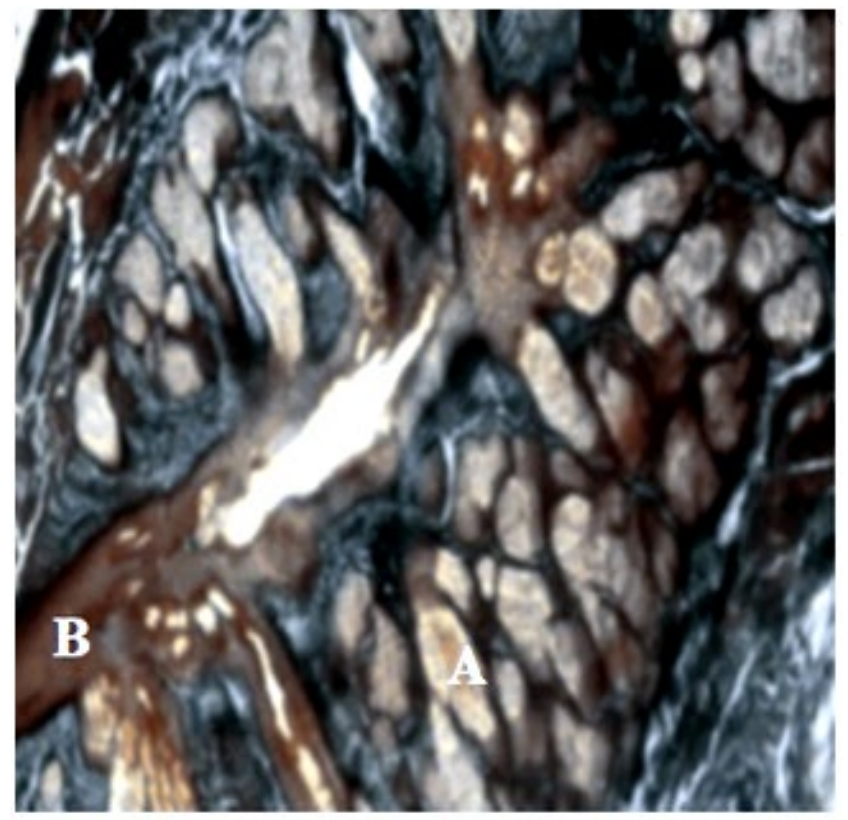

Fig. 1. Lower eyelid of Algerian local bovine, Masson Trichrome straining $\times 40$. A - tarsal gland, B - pilosebaceus duct 


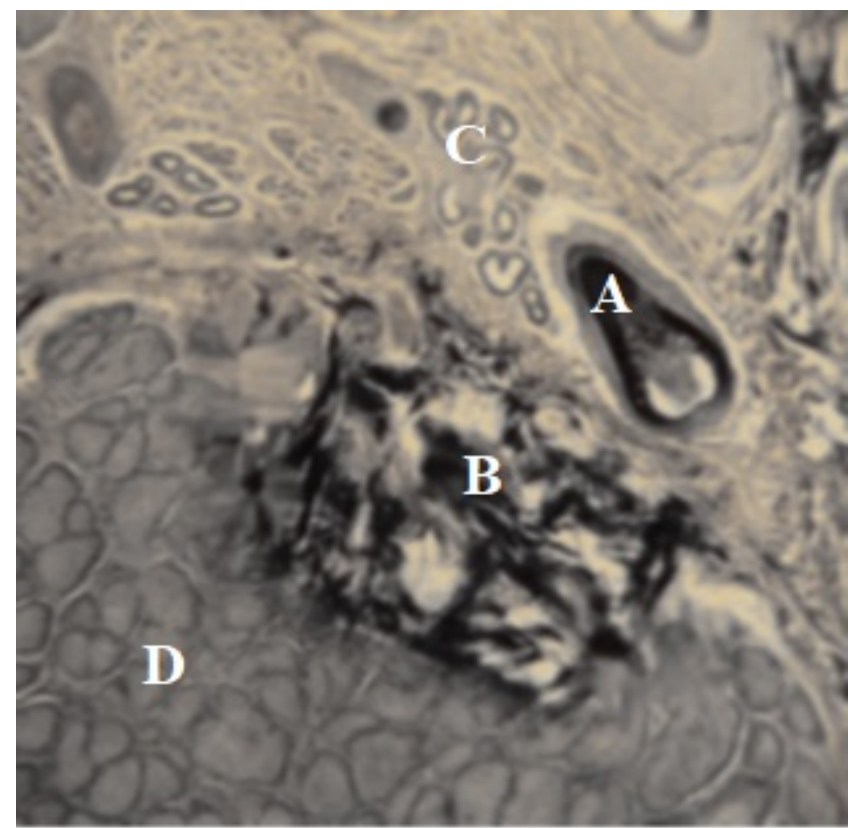

Fig. 2. Upper eyelid of Algerian local bovine. Silver nitrate staining $\times 40$. $\mathrm{A}-$ eyelashes follicule, $\mathrm{B}$ - elastic fiber, $\mathrm{C}$ - gland of Moll, D - Ttarsal gland

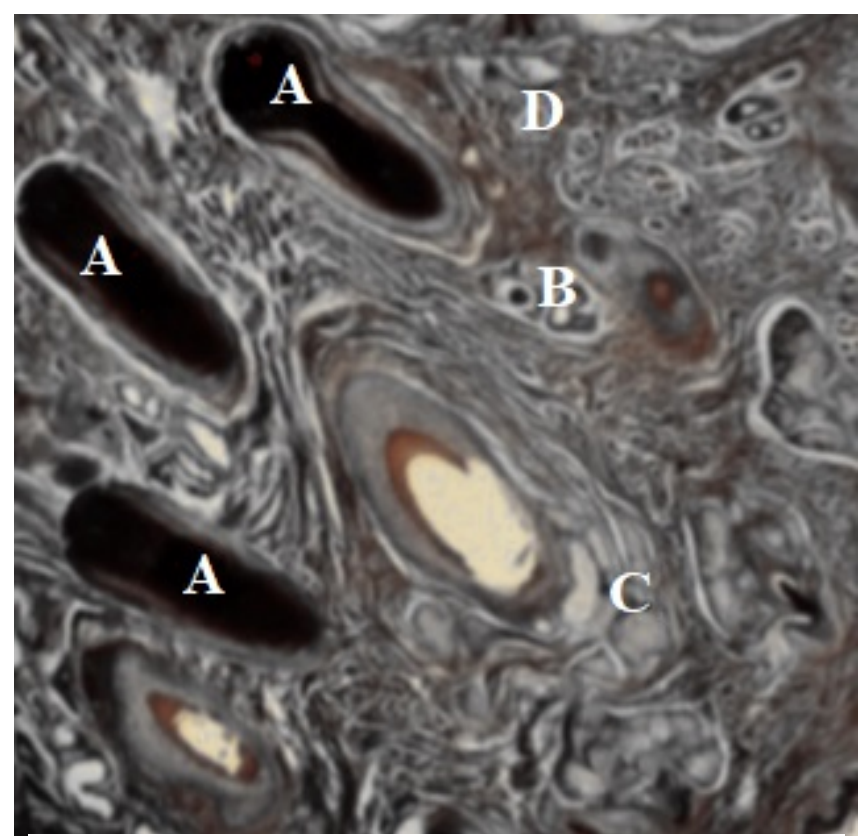

Fig. 3. Upper eyelid of Algerian local bovine. Masson Trichrome staining $\times 40$. A - eyelashes follicle, B - gland of Moll, C - gland of Zeis, D - muller muscles

\section{Discussion}

Thickness of epidermis of skin eyelids of Algerian local bovine varied according studied areas, the epidermis of lower eyelids is thick compared with other areas, wavier basement membrane, this increase in that surface area which assist in the nutrition, the same results found in the skin of black goat. The presence of melanocyte granule in stratum basal and hair follicle give color to eyelid skin and hair. Orbicularis muscle within tarsal plate are found, together they are made of large amount of collagen fibers and moderate amount of elastic fiber, the same finding appears in the eyelids of human that recorded these structures support eye lid traction, reinforcement structure and neutral barrier for the upper eyelid from conjunctivitis.

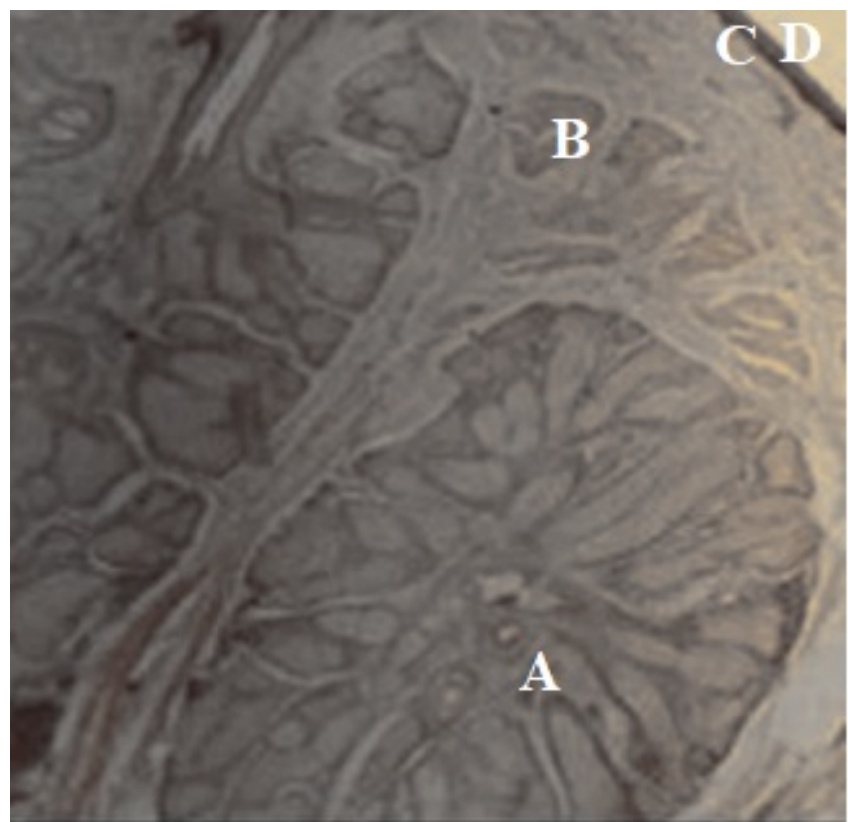

Fig. 4. Lateral conthus of eyelid, Hematoxylin \& Eosin staining $\times 40, \mathrm{~A}-$ tarsal gland, $\mathrm{B}-$ skeletal muscle, $\mathrm{C}-$ skin surface, D - external surface

Amakiri et al. (1979) referred that the superior tarsus is plate tissue that stiffens the upper eyelid of human gives it support and determines its form. The eyelashes are different in extension, it was clearly taller in upper eyelids than other areas, no investigators reported that, but the long eyelashes whom give protection for the eyes were arranged in double or triple rows, the same finding were reported in mammals by (Kakizaki et al., 2005). The present study revealed that the eyelashes devoid from arrector pili muscle, the same results reported in the eyelids of human, Marked differences in cell height and the formation of tall cell protrusion in gland of moll, represent typical feature of an apocrine secretary cell of sweat the same finding was be reported in skin of cow with (Fukuo et al., 1994) and human eyelids (Gartner et al., 2007; Biswas, 2014). Referred that the presence of sweat gland with different epithelial types in same section suggest that the glands are not in the same stage of secretion or that they may not be all activated at the same time which still unconfirmed till nowadays (Butler, 2008). Suggest that gland of moll play an important role in immune defense against bacteria and other pathogens in eyelid shaft and on the other ocular surface as found by (Hwan Moon, et al., 2018). The meibomian gland (Tarsal gland) of the local bovine of the upper eyelid are larger and near the epidermis compared with other studied areas. The same result was observed in Philippine buffalo (Milz et al., 2005) that recorded these glands were better developed in upper eyelids than lower eyelids. Tarsal gland better developed in upper eyelid than other areas, its diameter more than $5.79 \times 2.34 \mathrm{~mm}$ according to (Edward Gurr, 1959), others as reported that volume of sebaceous gland $(0.2-2) \mathrm{mm}$ in mammals and these glands have many function, like diminished microbes that enter skin, decrease loss of water, sebum contain vit D so the skin and hair remain smooth and pliable, while (Bank, 1986) reported that the secretion of these glands produced the oily tear film that retarded evaporation (Gartner et al., 2007). The previous factors assure that tarsal gland in upper eyelids more active in previous function than other studied areas. Gland of Zeis accompanied with eyelashes follicle (Sakai, 1981), which appear and disappear in lateral canthus areas compared with another studied areas (Zeiss et al., 2018), the present of these gland assist the 
function of tarsal gland. The percentage of goblet cells was high specially in internal part of conjunctiva as the results of (Gartner et al., 2007; Moon et al., 2018) was reported that the inner most layer of tear film produced by goblet cells of the conjunctival epithelium and lead to adherence of the precorneal film to the corneal surface (Schear et al., 2018).

\section{Conclusions}

The eyelids are mobile patches of skin that fold over the eyes, protecting them from external aggressions. In mammals, the eyelids are generally two in number, above and below, and the upper eyelid is the most mobile. But a certain number of them have a third eyelid: the nictitating membrane. The eyelashes - hairs on the free edge of the eyelids - help protect by blocking the dust before it reaches the cornea. In this research we made a histological study of the eyelid in Algerian local bovine, the observed results were significant, there was a small increase on the thickness of epidermis in lower eyelid, and the small sebaceous glands which was making difference between the lower eyelid of local bovine, these glands take their origins near to the basement membrane of the upper eyelids. About the tarsal gland, the secretion duct was determined and it was directly lined with typical stratified squamous epithelium. Eyelash follicle were variable in extension and diameter, arranged in double or triple rows. The follicle of eyelashes. They were many types of glands accompanied eyelash follicle, that have a significant difference especially on lower eyelid areas that also can be observed macroscopically, that eyelashes are longer in lower eyelid than in upper eyelid, these glands began near the basement membrane of the upper eyelids. Tarsal glands or meibomian glands; that are were well developed on the upper eyelids and near the surface of the skin in the same area. The related ducts were variable in extension, they were deeper in the upper eyelids than other studied areas.

\section{Conflict of interest}

The authors declare that there is no conflict of interest.

\section{References}

Amakiri, S. F., Ngere, L. O., Olusanya, S. K., \& Ikede, B. O. (1979). Crossbreeding of exotic and indigenous cattle in Nigeria-haematological correlates. Trop Anim Health Prod., 11(2), 106-112. doi: 10.1007/BF02237781.

Baker, J., \& Venditti, C. (2019). Rapid change in mammalian eye shape is Explained by activity pattern. Current Biology, 29(6), 1082-1088.e3. doi:10.1016/j.cub.2019.02.017.

Bank, W. J. (1986). Applied veterinary histology. 2nd ed. Baltimore: Williams \& Wilkins, 543-544.

Benoit, J., Abdala, F., Manger, P., \& Rubidge, B. (2016). The sixth sense in mammalians forerunners: variability of the parietal foramen and the evolution of the pineal eye in South African PermoTriassic eutheriodont therapsids. Acta Palaeontologica Polonica, 61(4), 777-789. doi: 10.4202/app.00219.2015.

Bharti, K., Liu, W., Csermely, T., Bertuzzi, S., \& Arnheiter, H. (2008). Alternative promoter use in eye development: the complex role and regulation of the transcription factor MITF. Development, 135(6), 1169-1178. doi: 10.1242/dev.014142.

Biswas, A. (2014). Eyelid anatomy. Eyelid Tumors, 1-18. doi: $10.1007 / 978-81-322-1874-61$

Butler, C. (2008). Joint review: William Outhwaite (ed.) The Blackwell Dictionary of Modern Social Thought, 2nd edition Oxford:
Blackwell Publishing, 2006, £21.99 pbk (ISBN 140513456 9), xvi+840 pp. William Outhwaite The Future of Society Oxford: Blackwell Publishing, 2006, £17.99 pbk (ISBN 063123186 2), $\mathrm{x}+174 \quad$ pp. Sociology, 42(4), 770-772. doi: $10.1177 / 00380385080420041102$.

Canals, M., Costa-Vila, J., Potau, J. M., Merindano, M. D., \& Ruano, D. (1999). Morphological study of cryopreserved human corneal endothelium. Cells Tissues Organs, 164(1), 3745. doi: 10.1159/000016641.

Cvekl, A., \& Wang, W.-L. (2009). Retinoic acid signaling in mammalian eye development. Experimental Eye Research, 89(3), 280291. doi: 10.1016/j.exer.2009.04.012.

Kakizaki, H., Zako, M., Nakano, T., Asamoto, K., Miyaishi, O., Miyagawa, T., \& Iwaki, M. (2005). Fibrous connective tissue between Müller's muscle and the palpebral conjunctiva as a reinforcement structure and a natural barrier for the upper eyelid. Okajimas Folia Anatomica Japonica, 82(3), 79-82. doi: $10.2535 /$ ofaj.82.79.

Fukuo, Y., Takeda, N., Hirata, H., Kato, T., Kadoi, C., Katayama, T., \& Kubota, Y. (1994). Immunohistological studies of an oncocytoma. Ophthalmologica, 208(5), 267-269. doi: $10.1159 / 000310506$.

Gartner, L. P., \& Hiatt, J. L. (2007). Integument. Color textbook of histology, 327-344. doi: 10.1016/b978-1-4160-2945-8.50016-8.

Gartner, L. P., \& Hiatt, J. L. (2007). Special senses. Color textbook of histology, 511-536. doi: 10.1016/b978-1-4160-2945-8.50024-7.

Hwan Moon, K., Kim, H.-T., Lee, D., Rao, M., Levine, E. M., Lim, D.-S., \& Kim, J. W. (2018). Differential expression of NF2 in neuroepithelial compartments is necessary for mammalian eye development. SSRN Electronic Journal. doi: 10.2139/ssrn.3155936.

Lang, R. A. (1997). Apoptosis in mammalian eye development: lens morphogenesis, vascular regression and immune privilege. Cell Death \& Differentiation, 4(1), 12-20. doi: $10.1038 /$ sj.cdd.4400211.

Methods of Analytical Histology and Histo-Chemistry. By Edward Gurr. The Williams and Wilkins Co., 428 East Preston St., Baltimore 2, Md., 1959. xv $+327 \mathrm{pp} .15 \times 24 \mathrm{~cm}$. Price $\$ 13$. (1960). Journal of the American Pharmaceutical Association (Scientific Ed.), 49(1), 62. doi: 10.1002/jps.3030490127.

Milz, S., Neufang, J., Higashiyama, I., Putz, R., \& Benjamin, M. (2005). An immunohistochemical study of the extracellular matrix of the tarsal plate in the upper eyelid in human beings. Journal of Anatomy, 206(1), 37-45. doi: 10.1111/j.00218782.2005.00363.x.

Sajdak, B. S., Salmon, A. E., Cava, J. A., Allen, K. P., Freling, S., Ramamirtham, R., ... Carroll, J. (2019). Noninvasive imaging of the tree shrew eye: Wavefront analysis and retinal imaging with correlative histology. Experimental Eye Research, 185, 107683. doi: 10.1016/j.exer.2019.05.023.

Sakai, T. (1981). The mammalian harderian gland: morphology, biochemistry, function and phylogeny. Archivum Histologicum Japonicum, 44(4), 299-333. doi: 10.1679/aohc1950.44.299.

Schear, M. J., \& Rodgers, R. (2018). A Case of Everolimusinduced eyelid edema. Ophthalmic Plastic and Reconstructive Surgery, 34(1), e21-e22. doi: 10.1097/iop.0000000000000974.

Schwarz, M., Alvarez-Bolado, G., Dressler, G., Pavel Urbánek, Busslinger, M., \& Gruss, P. (1999). Pax2/5 and Pax6 subdivide the early neural tube into three domains. Mechanisms of Development, $82(1-2), \quad 29-39$. doi: 10.1016/s09254773(99)00005-2.

Watt, K. I., Harvey, K. F., \& Gregorevic, P. (2017). Regulation of Tissue Growth by the Mammalian Hippo Signaling Pathway. Frontiers in Physiology, 8. doi: 10.3389/fphys.2017.00942.

Zeiss, C. J., Tu, D. C., Phan, I., Wong, R., \& Treuting, P. M. (2018). Special Senses. Comparative Anatomy and Histology, 445-470. doi: 10.1016/b978-0-12-802900-8.00021-x. 